\title{
Butylated hydroxytoluene can reduce oxidative stress and improve quality of frozenthawed bull semen processed in lecithin and egg yolk based extenders
}

\begin{abstract}
The aims of this study were to evaluate the effects of anti-oxidant butylated hydroxytoluene (BHT), when added at different concentrations into lecithin-based Bioxcell ${ }^{\circledR}(\mathrm{BX})$ and two egg-yolk-based; Tris (TY) and citrate (CE) semen extenders, on post-thaw bull sperm quality and oxidative stress. A total of 30 ejaculates from three bulls were collected using an electro ejaculator. Ejaculates were extended with one of the BX, TY and CE extenders, which contained different concentrations $(0.0$ - control, $0.5,1.0,1.5,2.0$ and $3.0 \mathrm{mM} / \mathrm{ml})$ of BHT. The extended semen samples were chilled to $4{ }^{\circ} \mathrm{C}$, and then frozen slowly to $-196{ }^{\circ} \mathrm{C}$ in $0.25 \mathrm{ml}$ straws before being stored in liquid nitrogen for 2 weeks. Results showed that supplementation of BHT improved $(P<0.05)$ general motility, progressive motility, morphology, acrosome integrity, DNA integrity and malondialdehyde of sperm at $0.5 \mathrm{mM} / \mathrm{ml}$ for BX and at $1-1.5 \mathrm{mM} / \mathrm{ml}$ of BHT for TY and CE when compared with the control. However, greater concentrations of 2.0 and $3.0 \mathrm{mM} / \mathrm{ml}$ of BHT had a detrimental $(P<0.05)$ effect compared with the control with all extenders evaluated. In conclusion, BHT supplementation at lesser concentrations $(0.5-1.5 \mathrm{mM} / \mathrm{ml})$ could improve frozen-thawed bull sperm quality by reducing oxidative stress produced during the freezing-thawing procedures in either lecithin or egg-yolk based extenders.
\end{abstract}

Keyword: Anti-oxidant; Butylated hydroxytoluene; Extender; Oxidative stress; Sperm quality 